\title{
Viewpoint: Making Sense of the Minefield of Footprint Indicators
}

Ridoutt, Bradley ; Fantke, Peter; Pfister, Stephan ; Bare, Jane; Boulay, Anne-Marie; Cherubini, Francesco ; Frischknecht, Rolf; Hauschild, Michael Zwicky; Hellweg, Stefanie; Henderson, Andrew Total number of authors:

23

Published in:

Environmental Science \& Technology (Washington)

Link to article, DOI:

10.1021/acs.est.5b00163

Publication date:

2015

Document Version

Peer reviewed version

Link back to DTU Orbit

Citation $(A P A)$ :

Ridoutt, B., Fantke, P., Pfister, S., Bare, J., Boulay, A-M., Cherubini, F., Frischknecht, R., Hauschild, M. Z., Hellweg, S., Henderson, A., Jolliet, O., Levasseur, A., Margni, M., McKone, T. E., Michelsen, O., i Canals, L. M., Page, G., Pant, R., Raugei, M., ... Wiedmann, T. (2015). Viewpoint: Making Sense of the Minefield of Footprint Indicators. Environmental Science \& Technology (Washington), 49(5), 26012603.

https://doi.org/10.1021/acs.est.5b00163

\section{General rights}

Copyright and moral rights for the publications made accessible in the public portal are retained by the authors and/or other copyright owners and it is a condition of accessing publications that users recognise and abide by the legal requirements associated with these rights.

- Users may download and print one copy of any publication from the public portal for the purpose of private study or research.

- You may not further distribute the material or use it for any profit-making activity or commercial gain

- You may freely distribute the URL identifying the publication in the public portal 


\section{Viewpoint: Making sense of the minefield of footprint indicators}

Bradley Ridoutt, ${ }^{*}$, , Peter Fantke ${ }^{b}$, Stephan Pfister ${ }^{c}$, Jane Bare ${ }^{\mathrm{d}, \neq}$, Anne-Marie Boulay ${ }^{\mathrm{e}, \mp}$, Francesco Cherubinif ${ }^{\mathrm{f}, \neq}$, Rolf Frischknecht ${ }^{\mathrm{g}, \neq}$, Michael Hauschild ${ }^{\mathrm{b}, \neq}$, Stefanie Hellweg ${ }^{\mathrm{c}, \mp}$, Andrew Henderson ${ }^{\mathrm{h}, \mp}$, Olivier Jolliet ${ }^{\mathrm{i}, \mp}$, Annie Levasseur ${ }^{\mathrm{e}, \mp}$, Manuele Margni ${ }^{\mathrm{e}, \mp}$, Thomas McKone $^{\mathrm{j}, \neq}$, Ottar Michelsen ${ }^{\mathrm{k}, \ddagger}$, Llorenç Milà i Canals ${ }^{\mathrm{l}, \mp}$, Girija Page ${ }^{\mathrm{m}, \ddagger}$, Rana Pant ${ }^{\mathrm{n}, \ddagger}$, Marco Raugei $^{0, \ddagger}$, Serenella Sala $^{n, \ddagger}$, Erwan Saouter ${ }^{n, \ddagger}$, Francesca Verones $^{\mathrm{f}, \neq}$, Thomas Wiedmann ${ }^{\mathrm{p}, \ddagger}$

${ }^{a}$ Commonwealth Scientific and Industrial Research Organisation (CSIRO), Clayton, Victoria 3169, Australia

b Technical University of Denmark (DTU), Department for Management Engineering, Division for Quantitative Sustainability Assessment, 2800 Kgs. Lyngby, Denmark

${ }^{c}$ ETH Zurich, Institute of Environmental Engineering, 8093 Zurich, Switzerland

d United States Environmental Protection Agency, Sustainable Technology Division, Systems Analysis Branch, National Risk Management Research Laboratory, Cincinnati, $\mathrm{OH} 45268$, USA

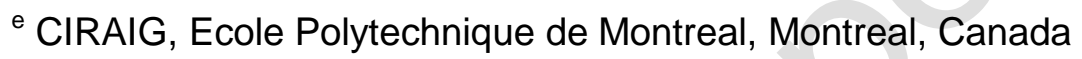

${ }^{f}$ Norwegian University of Science and Technology (NTNU), Industrial Ecology Programme, Department of Energy and Process Engineering, NO-7491 Trondheim, Norway

${ }^{g}$ treeze Ltd., Uster, Switzerland

${ }^{\mathrm{h}}$ University of Texas Health Science Center, School of Public Health, Division of Epidemiology, Human Genetics and Environmental Sciences, Houston, TX 77030, USA

' University of Michigan, School of Public Health, Environmental Health Sciences, Ann Arbor, MI 48109, USA

${ }^{j}$ University of California, Lawrence Berkeley National Laboratory and School of Public Health, Berkeley, CA 94720, USA

${ }^{\mathrm{k}}$ Norwegian University of Science and Technology (NTNU), Division for Finance and Property, NO-7491 Trondheim, Norway

' United Nations Environment Programme (UNEP), Division for Technology, Industry and Economics, 15 Rue de Milan, 75009 Paris, France

m University of Western Sydney, School of Science and Health, Penrith, NSW 2751, Australia 
${ }^{\mathrm{n}}$ European Commission, Joint Research Centre, Institute for Environment and Sustainability, Via Enrico Fermi 2749, Ispra, I-21027, Italy

${ }^{\circ}$ Oxford Brookes University, Department of Mechanical Engineering and Mathematical Sciences, Oxford OX33 1HX, United Kingdom

${ }^{\mathrm{p}}$ UNSW Australia, Sustainability Assessment Program, School of Civil and Environmental Engineering, Sydney, NSW 2052, Australia

Authors listed alphabetically

In recent years, footprint indicators have emerged as a popular mode of reporting environmental performance. The prospect is that these simplified metrics will guide investors, businesses, public sector policymakers and even consumers of everyday goods and services in making decisions which lead to better environmental outcomes. However, without a common "DNA", the ever expanding lexicon of footprints lacks coherence and may even report contradictory results for the same subject matter (1). The danger is that this will ultimately lead to policy confusion and general mistrust of all environmental disclosures.

Footprints are especially interesting metrics because they seek to express the environmental performance of products and organizations from a life cycle perspective. The life cycle perspective is important to avoid misleading claims based only on a selected life cycle stage. For example, the water used to manufacture beverages may be important, but if a beverage includes sugar, irrigation water used to cultivate sugarcane could be a greater concern. The focus on environmental performance distinguishes footprints from technical efficiency measures, such as energy use efficiency or water use efficiency, which typically only make sense when applied to a single life cycle stage as they lack local environmental context.

However, unlike technical efficiency, which can usually be accurately measured and verified, footprint indicators, with their wider view of environmental performance, are usually calculated using models which can differ in scope, complexity and model parameter settings. Despite the noble intention of using footprints to evaluate and report environmental performance, the potential inconsistency between different approaches acts as a deterrent to use in many public policymaking and business contexts and can lead to confusing and contradictory messages in the marketplace.

\section{Building on the international standards}

One way to achieve consistency in footprints is to start with the foundation of the international standards describing environmental management from a life cycle perspective, i.e. ISO 14040 and 14044. These international standards pre-date the recent broad-based popular interest in footprints and do not address the subject directly. Nevertheless, they are the global consensus documents underpinning life cycle assessment (LCA), which already supports a wide range of complex environmental decision-making in government and industry (2). 
The major distinction between LCA and footprints is that the former is oriented toward comprehensive assessment of all relevant environmental impacts and evaluation of tradeoffs, whereas the latter are more limited in scope, addressing only specific environmental subjects of societal concern. This leads to LCA study reports being rich in technical detail and although valuable in this regard, these reports are generally not widely accessible to people outside the field. This is in contrast to footprints which have a primary orientation toward non-LCA experts and society in general. Moreover, LCA practitioners work with a set of indicators defined by the LCA expert community (3). However, these LCA impact category indicators (e.g. terrestrial acidification, particulate matter formation, photochemical oxidant formation) are not necessarily the lens through which society views environmental protection.

All this is to say that while footprints should be based on LCA, they also have their own special characteristics. Already a wide range of individual footprint protocols reference ISO 14044: e.g. ISO TS14067, ISO 14046, PAS2050, GHG Protocol Product Standard, BPX 30-323-0. A task group established under the United Nations Environment Programme (UNEP) / Society of Environmental Toxicology and Chemistry (SETAC) Life Cycle Initiative is working on generic guidance to support the coherent development and application of footprint indicators addressing any subject of stakeholder concern - defined now or in the future (4).

\section{Defining attributes}

Footprints seek to condense complicated environmental information into a metric that society can use to make choices that can be expected to lead to improved environmental outcomes within the scope covered by the footprint. We have identified four defining attributes that should characterise all footprint indicators.

Environmental relevance: When aggregating data, having common units is necessary, but not sufficient; environmental equivalence is needed. To illustrate, it would not be environmentally meaningful to aggregate emissions of different greenhouse gases without first applying factors, such as those published by the Intergovernmental Panel on Climate Change describing the relative global warming potentials. Similarly, to assess the environmental performance of consumptive water use along a supply chain it is necessary to apply a model which accounts for differences in local water availability.

Accurate terminology: A footprint indicator addresses a specific subject of environmental concern and the indicator's name must reflect the scope and not be misleading. Where necessary, a qualifying term should be added. For example, following ISO 14046, the term water footprint is applied only when both consumptive and degradative (pollution) aspects of water use are assessed. When only consumptive water use is assessed, water scarcity footprint is a suggested alternative.

Directional consistency: Footprints need to follow a consistent logic whereby a smaller value is always preferable to a higher value. This facilitates the easy interpretation of footprints, which is important considering their orientation towards society and nontechnical stakeholders. 
Transparent documentation: Footprint methodologies and public footprint disclosures need to be supported by documentation enabling technical peer review. Study reports should document all methods, data sources and assumptions transparently and without bias.

From a technical perspective, footprint indicators might be based on life cycle inventory data (provided the environmental relevance criterion is satisfied), an existing LCA impact category indicator result, or the aggregation of results from different LCA impact categories of relevance to the topic of the footprint. Examples of these three types of footprints are: phosphorus depletion footprint, carbon footprint, and water footprint respectively.

\section{Multiple benefits}

In the European Union, the proliferation of inconsistent footprint methodologies has been identified as the underlying issue hampering the functioning of a market for green products (5). The benefits of harmonisation are many: reduced implementation costs for business, avoidance of market access barriers, a common basis for industry to seek out resource efficiency opportunities with supply chain partners, and increased consumer understanding and confidence that footprint communications are trustworthy (5). The solution we propose is the development of a coherent set of footprint indicators based on LCA.

\section{AUTHOR INFORMATION \\ Corresponding Author \\ *E-mail: brad.ridoutt@csiro.au}

\section{ACKNOWLEDGEMENTS}

This work is supported by the United Nations Environment Programme (UNEP) / Society of Environmental Toxicology and Chemistry (SETAC) Life Cycle Initiative. Public and private sector sponsors are listed on the Initiative's website (www.lifecycleinitiative.org/). The views expressed in this article are those of the authors and do not necessarily reflect those of the various affiliated organizations.

\section{REFERENCES}

(1) Fang, K.; Heijungs, R. Rethinking the relationship between footprints and LCA. Environ. Sci. Technol. 2015, 49 (1), 10-11.

(2) Hellweg, S.; Milà i Canals, L. Emerging approaches, challenges and opportunities in life cycle assessment. Science 2014, 344, 1109-1113.

(3) Jolliet, O.; Müller-Wenk, R.; Bare, J.; Brent, A.; Goedkoop, M.; Heijungs, R.; Itsubo, N.; Peña, C.; Pennington, D.; Potting, J.; Rebitzer, G.; Stewart, M.; Udo de Haes, $\mathrm{H}$.; Weidema, B. The LCIA midpoint-damage framework of the UNEP/SETAC Life Cycle Initiative. Int. J. Life Cycle Assess. 2004, 9, 394-404.

(4) Jolliet, O.; Frischknecht, R.; Bare, J.; Boulay, A.M.; Bulle, C.; Fantke, P.; Gheewala, S.; Hauschild, M.; Itsubo, N.; Margni, M.; McKone, T.E.; Mila y Canals, L.; Posthuma, L.; Prado-Lopez, V.; Ridoutt, B.; Sonnemann, G.; Rosenbaum, R.K.; Seager, T.; Struijs, J.; van Zelm, R.; Vigon, B.; Weisbrod, A. Global guidance on environmental life cycle impact assessment indicators: findings of the scoping phase. Int. J. Life Cycle Assess. 2014, 19, 962-967.

(5) European Commission, Communication from the Commission to the European Parliament and the Council. Building the single market for green products: 
174

175

176

177 FIGURES

178

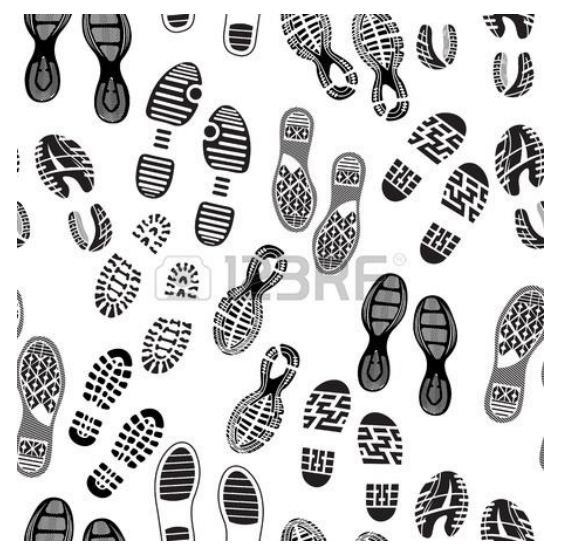

179 Figure 1. Many types of environmental footprints pointing in different directions make for policy confusion and contradictory messages in the marketplace. This problem can be overcome if footprints describing environmental performance are based on life cycle assessment (LCA).

Image license to be obtained: http://www.123rf.com/photo 20503891 imprint-soles-shoespattern.html?term=footprints 